\title{
29
}

\section{Applications of Positive Organizational Scholarship in Institutions of Higher Education}

\author{
Kim Cameron
}

A broad and well-developed literature has been produced over the last two decades demonstrating the beneficial effects of positive psychology and positive practices in educational settings, primarily focusing on student wellbeing and student academic performance (e.g., Adler, 2016; Seligman, Ernst, Gillham, Reivich, \& Linkins, 2009; Waters, Sun, Rusk, Cotton, \& Arch, 2015; White \& Murray, 2015). This volume is a testament to the impact of positive educational interventions across multiple cultures. However, these interventions have focused primarily on students and staff members as individuals. What has received less attention is the effect of positive practices on the educational institutions themselves, and especially on institutions of higher education-colleges and universities. The scholarly literature examining organizations and the relationship between positive practices and institutional performance is much less well-developed (Cameron, 2014).

This is not only because student wellbeing and student academic performance are such important outcomes in education, but also because of the difficulty in measuring organization-level outcomes in higher education (Cameron, 1978, 1980). Colleges and universities are primarily loosely coupled systems whose units frequently operate in a semi-autonomous fashion and whose criteria for indicating effectiveness are ambiguous. Desirable outcomes are frequently independent and even conflicting. Relevant constituencies often have contradictory or mutually exclusive goals. A typical

\footnotetext{
K. Cameron $(\varangle)$

University of Michigan, Ann Arbor, MI, USA

e-mail:kim_cameron@umich.edu
} 
university, for example, is in the business of competing for research grants and improving teaching, elevating student retention and maintaining exclusive entrance requirements, elevating annual giving and fostering fiscal efficiency, generating high starting salaries for graduates and pursuing public service, maintaining desirable student housing and investing in competitive intercollegiate athletics, providing a conducive social environment and carefully monitoring underage drinking and sexual harassment. Maximizing one outcome may mitigate the attaining of other outcomes, so identifying an overall set of indicators of institutional performance is difficult. Identifying overall institutional effectiveness in higher education has long been a conundrum in the academic literature (Cameron, 1981, 2010).

The development of Positive Organizational Scholarship (POS), however, has helped to put focus on the positive practices of institutions themselves rather than on individual members or the activities in subunits of the university. To explain this assertion, POS is first described, and then the application of POS to institutions of higher education is discussed. Two case studies highlight that POS has an important influence on the performance of colleges and universities as entities.

\section{Positive Organizational Scholarship and Organizational Performance}

Positive organizational scholarship is an umbrella framework used to unify a variety of concepts in organizational studies, each of which incorporates the notion of the positive. One way to illustrate the approach taken by POS to organization-level performance is to locate it on a continuum, represented in Fig. 29.1. This continuum depicts a state of expected or effective performance in the middle (meeting expectations and goals), with a condition of negatively deviant performance on the left (missing targets, making mistakes, offending constituencies) and a state of positively deviant performance on the right (extraordinary success, far-exceeding goals, and aspirations). Negative and positive deviance refer to aberrations from effective functioning or expected performance, harmful on one end and virtuous on the other end. The figure portrays performance ranging from ineffective, inefficient, and error-prone performance on the left side, to effective, efficient, and reliable performance in the middle, to extraordinarily positive organizational performance (e.g., virtuous, excellent, flawless, flourishing) on the right side. The extreme right and left points on the continuum do not merely represent 


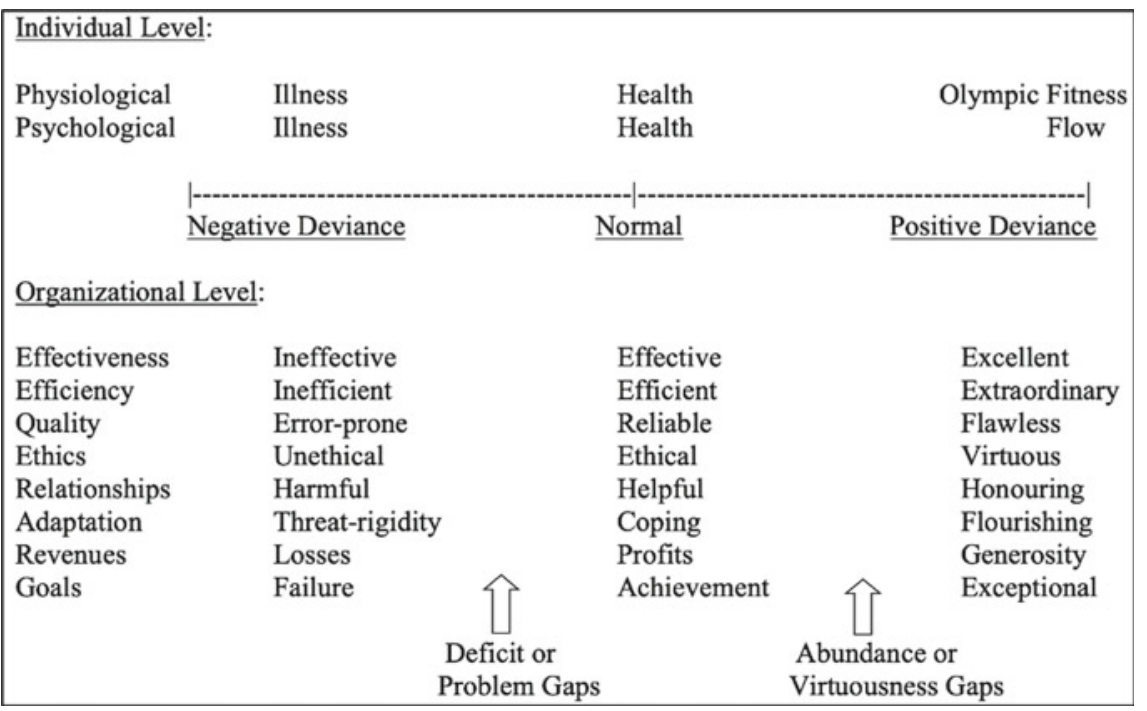

Fig. 29.1 A continuum illustrating positive deviance (Adapted from Cameron [2003])

a greater or lesser quantity of the middle attributes. They are qualitatively distinct from the centre point.

A large majority of published studies on organizational and institutional performance have focused on the middle of the continuum-goal achievement, obtaining necessary resources, solving problems, satisfying constituencies, attaining quality, generating revenues, engaging employees, and so forth. In higher education, in particular, the dominant emphasis has been on criteria such as accreditation, graduation rates, faculty publishing, research grants, teaching quality, and student ratings (e.g., Bowen, 1977; Cameron, 1978; Makhoul, 2019; Pursglove \& Simpson, 2007). Achieving basic organizational effectiveness at the centre of the continuum dominates evaluations, and little attention has been given to the flourishing or spectacular aspects of organizations. The criteria for enabling the achievement of the right end of the continuum have largely been ignored (Cameron, Dutton, \& Quinn, 2003; Cameron \& Spreitzer, 2012). Too little is known about positively deviant performance and the criteria that represent it. Well-developed concepts are still under-developed to explain performance on the right side of the continuum. A POS approach centres on these ill-defined and nascent phenomena—namely, positive deviance and extraordinary performance.

The concepts describing the right end of the continuum have frequently been associated with non-scholarly prescriptions or uncritical ecumenicalism (Peterson \& Seligman, 2004). Virtuousness, for example, has often been rejected as saccharine, anti-intellectual, or morally dogmatic (Sandage \& 
Hill, 2001). Flourishing has been interpreted as wishful thinking or naiveté (Scheier, Carver, \& Bridges, 1994). Prosocial behaviour and an abundance approach to performance have been dismissed as merely disguised motives for manipulating others and obtaining personal gain (Cialdini, 2000). On the other hand, some POS research has begun to tackle the definition and measurement issues associated with these concepts, and empirical evidence has begun to emerge linking certain organizational dynamics to extraordinarily positive levels of performance (Cameron, Bright, \& Caza, 2004; Cameron \& Lavine, 2006; Cameron, Mora, Leutscher, \& Calarco, 2011; Dutton \& Glynn, 2008).

\section{Origins of POS}

Unlike positive psychology, POS did not emerge as an attempt to rebalance the prodigious emphasis on illness and languishing in organizations. Organizational research has not been focused overwhelmingly on failure, damage, and demise. In fact, studying organizational decline was first introduced in organizational studies in 1980 (Whetten, 1980) because most organizational theories focus almost exclusively on growth. Big has almost always been assumed to be better than small; getting more is preferable to getting less; growth is better than stability (or, worse yet, stagnation). Negative phenomena do not dominate organizational studies literature as they did in psychology, even though plenty of attention has been paid to alienation, stress, injustice, and the evils of bureaucracy in traditional organizational studies (e.g., Weber, 1997).

Rather, POS arose because an array of organizational phenomena was being ignored; consequently, such phenomena were neither systematically studied nor valued. It was usually not considered legitimate in organizational studies, for example, to discuss the effects of virtues in organizations or to use terms such as flourishing or positive deviance to describe outcomes. Studies of compassion and forgiveness - two of the early studies in the POS literature (Cameron \& Caza, 2002; Dutton, Worline, Frost, \& Lilius, 2006)—diverged from mainstream organizational science. Similarly, certain kinds of organizational processes - for example, generative dynamics-remained largely un-investigated, including high-quality connections (Dutton \& Heaphy, 2003), thriving (Spreitzer, Sutcliffe, Dutton, Sonenshein, \& Grant, 2005), connectivity (Losada \& Heaphy, 2004), and positive energy networks (Baker, Cross, \& Wooten, 2003). 
To be sure, ample research has been conducted on positive factors such as subjective wellbeing, corporate citizenship, prosocial behaviour, positive affect, positive identity, engagement, psychological capital, and satisfaction (e.g., Diener, 2009; Luthans, Norman, Avolio, \& Avey, 2008). Investigations of organizational citizenship behaviour (OCB) have uncovered relationships, for example, between $\mathrm{OCB}$ and sales performance and human resource practices (Podsakoff, Mackenzie, Paine, \& Bachrach, 2000). Most of the outcomes in these studies, however, focus on the individual level of analysis rather than on the organization's performance per se (Moore \& Beadle, 2006).

Relationships between positive organizational dynamics and individual outcomes have been verified but appear much more frequently than relationships with organizational outcomes. For example, evidence exists that positive practices (e.g., respectful treatment, personal development) produce positive affect in employees (e.g., satisfaction, wellbeing), which, in turn, produces positive individual behaviour (e.g., retention, engagement), which, in turn, is assumed to produce organizational effectiveness (e.g., profitability, productivity) (see Cameron et al., 2011; Lyubomirsky, King, \& Diener, 2005). But, the last link in this chain is, as yet, underexamined. The connection between positive practices and organizational effectiveness needs much more empirical confirmation (Chun, 2005; Wright \& Goodstein, 2007). This is especially true regarding educational organizations and, more particularly, institutions of higher education where the research is especially sparse.

POS also arose because the outcome variables that dominated the organization literature focused mainly on profitability, competitive advantage, shareholder value, and economic efficiency (Davis \& Marquis, 2005; Goshal, 2005; Jensen, 2002). Granted, outcomes such as job satisfaction, justice, and teamwork also appeared throughout the organizational studies literature (Guzzo \& Dickson, 1996; Kramer, 1999; Smith, Kendall, \& Hulin, 1969), but alternative outcomes such as psychological, social, and eudaemonic wellbeing (Gallagher, Lopez, \& Preacher, 2009; Keyes, 2005)—including social integration, social contribution, social coherence, social actualization, and social acceptance_-as well as human sustainability (Pfeffer, 2010), have been largely outside the purview of mainline organizational science. The best of the human condition - what people care about deeply and profoundlywas almost invisible in organizational scholarship. The famous statement by Robert Kennedy in an 18 March 1968 speech at the University of Kansas is particularly illustrative:

The gross national product does not allow for the health of our children, the quality of their education, or the joy of their play. It does not include the 
beauty of our poetry or the strength of our marriages, the intelligence of our public debate, or the integrity of our public officials. It measures neither our wit nor our courage, neither our wisdom nor our learning, neither our compassion nor our devotion to our country. It measures everything, in short, except that which makes life worthwhile.

\section{Early Foundations of POS}

Positive psychology might be argued to have a long history, dating back to William James' (1902) writings on what he termed "healthy mindedness", Allport's (1960) interest in positive human characteristics; Jahoda's (1959) emphasis on prevention-based community psychology; Maslow's (1968) advocacy for studying healthy people in lieu of sick people; Diener's (1984) investigations of happiness and subjective wellbeing; and Organ (1988) and Batson's (1994) consideration of "citizenship behaviours" and "prosocial" activities.

Similarly, POS could be argued to have roots in a "new attitude of optimism and hope" (Bennis, 1969, p. 3) as emphasized in The Human Side of Enterprise (McGregor, 1960). This was a reaction to the dehumanizing and economically directed emphases in work organizations. Cooperrider and Srivastva's (1987) introduction of appreciative inquiry spotlighted the positive dynamics associated with planned change and organizational development efforts. POS, therefore, is not as much a new field of investigation as it is a coalescing force that brings together themes, perspectives, and variables that have been dispersed in the literature and underdeveloped or ignored in scientific investigation.

Most importantly, most of this earlier positively themed work was not based on scientific research and empirical investigations. It largely focused instead on advocacy and promoting a value-based approach to addressing problems, overcoming ills, and resolving difficulties (e.g., Bennis, 1963; Maslow, 1965). Moreover, little of this work explicitly addressed organizations as the entities of interest. The emergence of POS, therefore, does more than merely construct a repository for earlier work. It highlights the organization as a context for study and, at the same time, emphasizes the importance of multiple levels of analyses including individuals, groups, and societies. As such, POS highlights processes and practices that occur in organizations that are associated with positive outcomes in ways that build upon prior work and perspectives, but with a specific focus that opens up new possibilities for organizations. 


\section{Key Attributes of POS}

The key characteristics of POS can be captured by four elements: a positive lens, a focus on the extraordinary, an affirmative bias, and the examination of virtuousness at the organizational level.

The first element relates to the interpretation or approach to the term "positive". Positive refers to adopting a unique lens or an alternative perspective. Adopting a POS lens means that the interpretation of phenomena is altered. For example, challenges and obstacles are reinterpreted as opportunities and strength-building experiences rather than as tragedies or problems (Gittell, Cameron, Lim, \& Rivas, 2006; Lee, Caza, Edmondson, \& Thomke, 2003; Sutcliffe \& Vogus, 2003). Variables not previously recognized or seriously considered become central, such as positive energy (Baker, Cross, \& Wooten, 2003); moral capital (Godfrey, 2003); flow (Quinn, 2002); inspiration (Thrash \& Elliot, 2003); compassion (Dutton et al., 2006); elevation (Vianello, Galliani, \& Haidt, 2010); and work callings (Wrzesniewski, 2003) in organizations. Adopting a POS lens means that adversities and difficulties reside as much in the domain of POS as do celebrations and successes, but a positive lens focuses attention on the life-giving elements or generative processes associated with these phenomena. It is the positive perspective-not the nature of the phenomena - that situates an issue into the POS domain.

The second element of POS is a focus on extraordinarily positive outcomes or positively deviant performance in organizations (Spreitzer \& Sonenshein, 2003). This means that outcomes are investigated that dramatically exceed common or expected performance. A number of studies have investigated spectacular results, surprising outcomes, and extraordinary achievements (e.g., Gittell et al., 2006; Hess \& Cameron, 2006; Tutu, 1999; Worthington, 2001), with each treating "positive" as synonymous with exceptional performance. Reaching a level of positive deviance, in other words, extends beyond achieving effectiveness, or ordinary success. Instead, it represents "intentional behaviours that depart from the norm of a reference group in honourable ways" (Spreitzer \& Sonenshein, 2003, p. 209). For example, Cameron and Lavine (2006) investigated the closure and clean-up of the Rocky Flats Nuclear arsenal, the most polluted site on the North American continent, which had produced the triggers that went into nuclear weapons produced during the Cold War. It was estimated that the clean-up of the site would take 70 years and cost $\$ 36$ billion dollars. The project exceeded federal clean-up standards by a factor of 13 , was completed 60 years early, and was $\$ 30$ billion under budget. Baker and Gunderson (2005) examined how the number-onerated delicatessen in America-located in Ann Arbor, Michigan-achieved 
that distinction. Tutu (1999) highlighted the cultural and organizational transformations that occurred in South Africa upon the release of Nelson Mandela from 27 years in prison on Robben Island. Other studies have illustrated the extraordinary success of some financial services organizations that adopted POS as a corporate strategy (Cameron, 2012; Cameron \& Plews, 2012; Cameron \& Powley, 2008). Such studies have investigated the indicators of and explanatory processes accounting for positively deviant performance, identifying what leads to the extraordinary over the usual.

A third element represents an affirmative bias that fosters resourcefulness. POS presumes that positivity unlocks and elevates resources in individuals, groups, and organizations, so that capabilities are broadened and capacity is built and strengthened (Fredrickson \& Joiner, 2002; Fredrickson, 2009). POS is unapologetic in emphasizing affirmative attributes, capabilities, and possibilities more than problems, threats, and weakness, so that strengthsbased activities and outcomes are highlighted (Clifton \& Harter, 2003). Notably, this affirmative approach does not exclude consideration of negative events. Rather, these are incorporated in accounting for life-giving dynamics, generating resources, and flourishing outcomes (e.g., Dutton et al., 2006; Dutton \& Glynn, 2008; Weick, 2003). This affirmative bias leads to resourcefulness rather than scarcity.

Resourcefulness means that individuals and organizations experience an amplifying effect when exposed to positivity, such that resources and capacities expand (Dutton \& Sonenshein, 2009; Fredrickson \& Joiner, 2002). In addition, all living systems have a heliotropic inclination (Erhard-Seibold, 1937). That is, every human being has a tendency towards positive, life-giving energy and away from negative, life-depleting energy (Cameron, 2012). In the scholarly literature, human energy is classified as taking one of two forms-(1) activation potential, or the capacity to do work, indicated by the amount of glucose/glycogen and adenosine triphosphate (ATP) in the body, and (2) energetic stimulation, or the feeling of aliveness, enthusiasm, and vitality. Abundant empirical evidence suggests that exposure to positive phenomena is, literally, life-enhancing in that it strengthens and enhances this second form of energy (Cooperrider \& Srivastra, 1987; Diener, 2009; Loeb $\&$ Northrup, 1917; Northrop \& Loeb, 1923). Adopting an affirmative bias, therefore, enhances positive energy in organizations (Cameron, 2012, 2013), and increases the capacity of organizations to effectively address difficult challenges and negative events (Clifton \& Harter, 2003; Losada \& Heaphy, 2004; Worline \& Quinn, 2003).

A fourth element refers to the examination of virtuousness or the best of the human condition at the organizational level. POS is based on a eudaemonic 
assumption - that is, the postulation that an inclination exists in all human systems towards achieving the highest aspirations of humankind (Aristotle, 2018; Dutton \& Sonenshein, 2009). Studying virtuousness in organizations means examining excellence and goodness for its own sake-captured by the Latin virtus and the Greek arête. Although debate has arisen regarding what constitutes goodness and whether universal human virtues can be identified, all societies and cultures possess catalogues of traits that they deem virtuous, that represent what is morally good, and that define the highest aspirations of human beings (Comte-Sponville, 2001; Peterson \& Seligman, 2004).

Positive organizational scholarship examines the development of and the effects associated with virtuousness and eudaemonism specifically in organizations (Bright, Cameron, \& Caza, 2006; Cameron, 2003; Ilies, Nahrgang, \& Morgeson, 2007), or "that which is good in itself and is to be chosen for its own sake" (Aristotle, 2018, p. 3). Studies of virtuousness in organizations focus on individuals' behaviours in organizational settings that help others flourish (Fowers \& Tjeltveit, 2003), including investigating character strengths, gratitude, wisdom, forgiveness, hope, and courage (Grant $\&$ Schwartz, 2011; Luthans, et al., 2008). Studies of virtuousness through organizations focus on practices and processes that represent and perpetuate what is good, right, and worthy of cultivation by organizations (McCullough \& Snyder, 2001; Park \& Peterson, 2003). This includes, for example, investigating profound purpose and transcendent objectives (Emmons, 1999); healing routines (Powley \& Piderit, 2008); institutionalized forgiveness (Cameron \& Caza, 2002); and human sustainability (Pfeffer, 2010).

These four elements of POS-adopting a positive lens, investigating extraordinarily positive performance, espousing an affirmative bias, and exploring virtuousness or eudaemonism-are not exclusively the domain of POS, but they do identify the scholarly territory that POS scholars are attempting to map. Similar to other concepts in organizational science that do not have precisely bounded definitions (e.g., culture, innovation, core competence), this mapping provides the conceptual boundaries required to locate POS as an area of inquiry.

Applying POS in higher education, therefore, implies that the entire institution is the target of investigation-the culture, the processes, the goals, and the interaction patterns. Affecting the institution as a whole, in turn, would be expected to positively influence individual students, staff, faculty, and external constituencies. Not only should outcomes such as test scores, student wellbeing, and classroom activities be enhanced, but evidence should indicate that the institution itself has adopted a positive lens and an affirmative bias, has achieved extraordinary performance, and is typified by eudaemonism. 


\section{Applications of POS in Higher Education}

The investigation and application of POS in colleges and universities has, unfortunately, rarely been documented. Most studies in higher education have focused on individual student learning outcomes or the effectiveness of specific functions such as career counselling or student placement (e.g., Allan, 1996). Individual outcomes rather than collective level performance have been the primary focus.

Recently, two investigations were conducted in higher education institutions in which POS had been adopted as the core foundation upon which the future culture and strategy of each institution were to be based. These two investigations are presented as illustrations of the potential of POS to enhance the performance of institutions as a whole as well as to enhance student success. One case represents a very large, multinational consortium of universities that adopted POS as the basis upon which their strategy, culture, and approach to higher education would be based going forward. A second case represents a university in Mexico that adopted POS as the core philosophy designed to help the institution overcome a major decline in performance. Each case is described briefly, and the outcomes and lessons learned are summarized. The intent of presenting these two cases is to highlight certain positive organizational practices that affected institutional performance.

\section{Laureate}

A first example of the application of POS at the institutional level emerged from a study of the world's largest university consortium-Laureate-which, in 2017, owned 69 universities in 12 regions throughout the world (https:// laureate.net). At the time, Laureate represented more than one million students and approximately 135,000 staff members. ${ }^{1}$ These institutions are located in Central and South America, Australia, New Zealand, Europe, India, and Africa, and several of them are considered to be the most prestigious in their respective nations. Many of these institutions are located in economically underdeveloped places in the world, so the oft-cited criticism that positive practices, positive psychology, and POS are relevant only in

\footnotetext{
${ }^{1}$ In 2019, stock market pressures and demands for increased profitability, as well as influence from the non-resident founder of the company, pressured Laureate into selling off all of their universities worldwide except those located in South. These financial pressures resulted in the senior leaders at Laureate focusing almost exclusively on the task of consolidating and downsizing the organization. As of this writing, the organization is still going through retrenchment and is shedding universities in order to pay down debt and increase stock price.
} 
economically well-developed areas of the world is countered by the experience of these universities.

The Chief Executive Officer (CEO) (Eilif Serck-Hanssen) and the president (Ricardo Berckemeyer) of Laureate determined that a focus on POS would be the core principle around which innovation and culture change would be based in the future. Laureate was facing significant financial pressures and senior executive turnover, so the status quo, it was determined, was not a viable strategy for future success. These two leaders had become exposed to POS through interactions with Jim Mallozzi-a former CEO of one of the Prudential Financial Services businesses and an ardent practitioner of POS leadership - as well as with the author.

A systematic process was developed by the Laureate senior team, including the human resource staff, in which it was determined that the leadership of the entire worldwide organization and all its colleges and universities would be trained in POS. The particular emphasis was to be on positive leadership practices. Figure 29.2 illustrates the stages that were developed by senior executives in Laureate to expose the entire university system to the POS approach and the implementation of positive leadership.

The first step was to bring together the senior leaders in the Laureate organization, as well as presidents, chancellors, and chief academic officers of the various universities throughout the world, for a three-day intensive

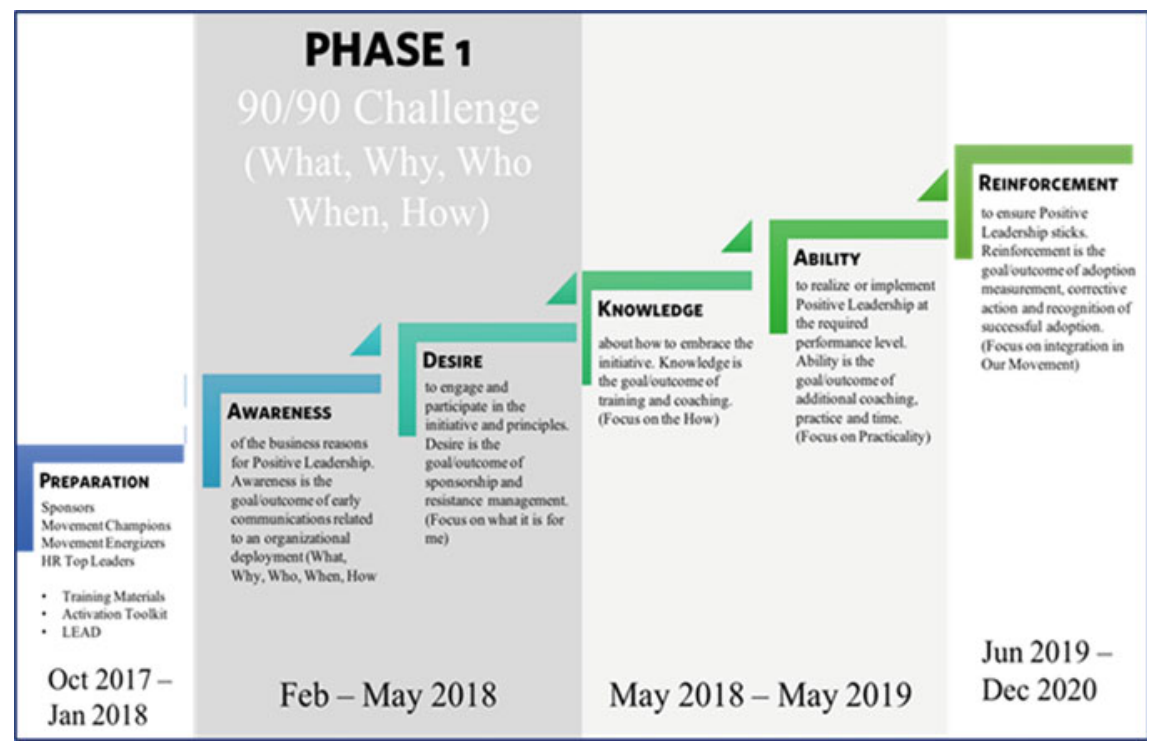

Fig. 29.2 Framework used at Laureate to expose the university to positive organizational scholarship and positive leadership 
workshop. The workshop centred on reviewing the empirical research that established the credibility for a POS approach to institutional performance as well as identifying practical tools and applications that leaders could institutionalize in their various universities (e.g., Cameron, 2012, 2013; Whetten \& Cameron, 2020).

Participants were exposed to empirical evidence that demonstrates the impact of positive organizational practices on bottom-line institutional performance as well as on students, staff, and faculty members. In addition, a variety of practical tools including those related to leader-subordinate relationships, supportive communication, culture diagnosis and change, gratitude, contribution and generalized reciprocity, high-quality connections, and positive energy were discussed and demonstrated.

As part of the workshop, participants identified "positive energizers" in each of the 12 geographic regions. Positive energizers are individuals who engender positive relationships, convey enthusiasm, help other people flourish, and can be relied upon to uplift and elevate the climate of their units. The senior executives from each institution worldwide identified 46 positive energizers. These positive energizers were brought together for a three-day intensive workshop on positive leadership and positive organizational practices. Similar to the senior executives in each institution, they were exposed to a variety of positive leadership practices and given a 90-in-90 Challenge. The challenge was stated as: " 90 percent of all staff members throughout the world will be infected with positive leadership and POS in 90 days". To infect meant that individuals could teach or explain POS and positive leadership practices, and they would have attempted a $1 \%$ improvement aimed at implementing POS.

After returning from the workshop to their various locations, positive energizers selected additional positive energizers in their various universities to assist them with the 90 -in-90 challenge. No centrally prescribed agenda was mandated for how this 90 -in-90 challenge was to be approached, and energizers were free to approach the task in whatever ways they felt appropriate. Figure 29.3 illustrates a variety of approaches these various groups used to accomplish the task.

In 90 days, ending in May 2018, 93.3\% of the 135,000 staff members had been infected with positive leadership, and more than 120,000 hours of training and workshops had been conducted. Forums, seminars, celebrations, task forces, classroom instruction, coaching, and theatrical productions were developed to accomplish the task. Almost all (99\%) of contractors, interns, and temporary employees joined with full-time employees in participating in the activities. In follow-up surveys conducted after the events, $95 \%$ of 


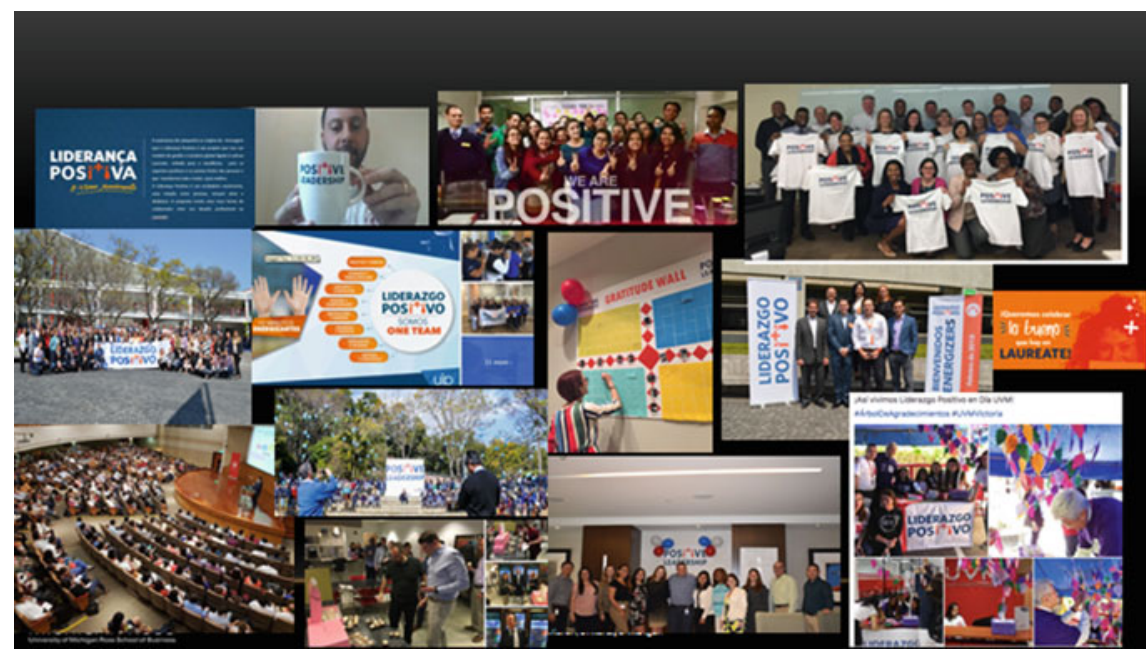

Fig. 29.3 Approaches developed by the positive energizers to accomplish the 90 -in90 challenge

participants indicated that they would recommend the training to others, and 98\% indicated that they gained new knowledge on how they could enhance their institution's performance.

Eight dimensions of positive practices were assessed at the end of the 90day intervention, which assessed attributes of the overall Laureate organization as rated by staff members. These dimensions include: Dignity and Respect (the extent to which the institution fosters dignity and respect for employees), Meaningfulness and Purpose (the extent to which the institution emphasizes the significance and higher purpose of the work), Trust and Integrity (the extent to which the institution expects and fosters integrity among employees), Gratitude and Appreciation (the extent to which the institution demonstrates and encourages gratitude and appreciation of employees), Caring and Concern (the extent to which the institution helps employees feel valued and cared for), Support and Compassion (the extent to which the institution provides emotional and social support to employees who are struggling), Forgiveness and Understanding (the extent to which the institution demonstrates forgiveness and understanding when mistakes are made), and Inspiration and Positive Energy (the extent which the institution energizes and inspires employees). Figure 29.4 shows the scores on these dimensions after the POS training compared to the previous benchmark scores. On each dimension, scores had slightly improved in the three-month period.

In addition to the overall institutional strategies that were implemented, 14 different experiments were conducted to assess the impact of POS on 


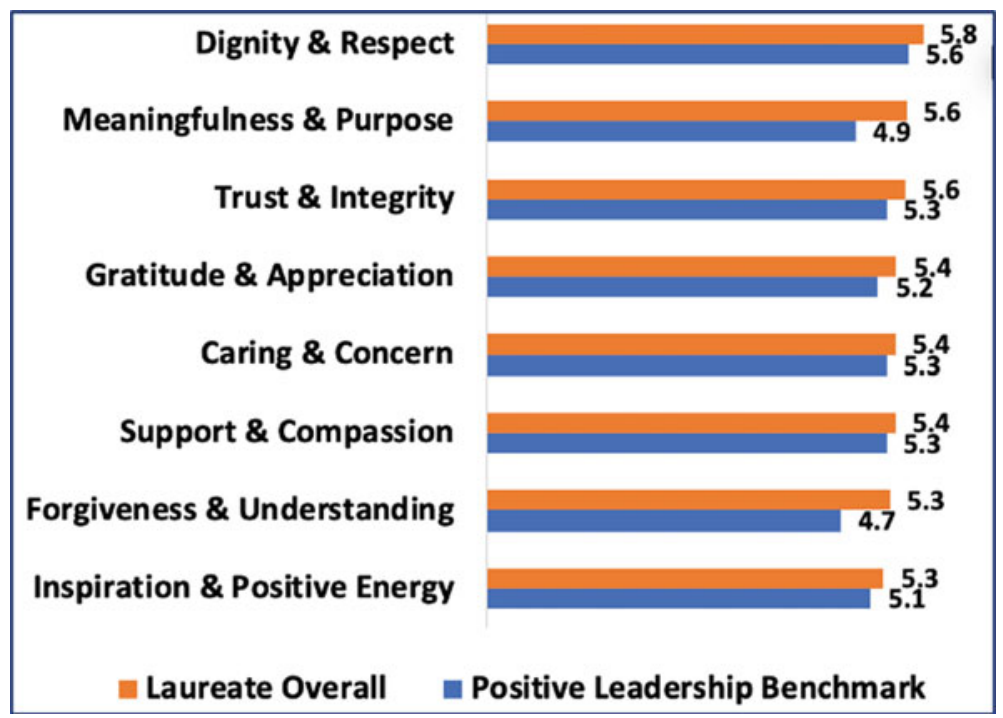

Fig. 29.4 Scores on eight dimensions of positive practices

students in classrooms. In several Laureate universities located in India, Peru, and Spain, instructors across a variety of disciplines volunteered to participate in the study. They agreed to implement a variety of POS practices in their classrooms, but no prescribed curriculum or approach was designated. The disciplines in the study included Accounting, Analytic Design Methods, Architecture, Art, Economics, Education, Human Resources, Nutrition, Physiology, and Statistics. Instructors were exposed to positive leadership practices in a workshop and then asked to incorporate whatever practices they desired in their classrooms. Data were collected comparing the POS classes to previous classes taught by the same instructors the year before. Figure 29.5 provides the comparisons.

In a university in India, student satisfaction scores in the courses that used POS practices were almost a full point higher on a 1-5 scale than courses without a POS approach the year before. In another analysis of six separate classrooms at the same university, average student test scores and grades were significantly higher compared to the year before, and student attendance was $10 \%$ higher compared to the instructors' courses the year before. In four separate classrooms in a Spanish university, average student test scores and course grades were half a point higher in the POS classes compared to the previous non-POS classes.

These are not rigorously controlled experiments and clearly a variety of other factors may be at play in accounting for the results. The outcomes do 


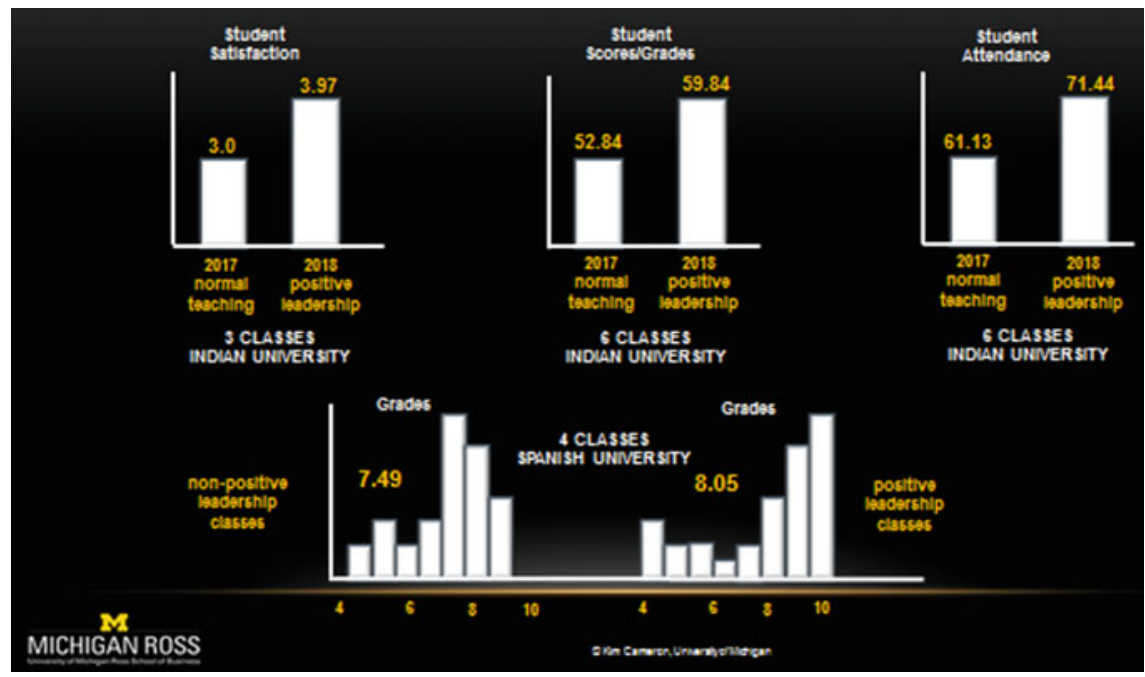

Fig. 29.5 Effects of positive leadership classes on students at universities in India, Peru, and Spain

suggest, however, that positive practices had a non-trivial impact on the institutions and on students in the classroom even across different disciplines and cultures.

\section{Tecmilenio}

A second institutional example of the effects of POS on performance is Tecmilenio University in Monterrey, Mexico (https://tecmilenio.mx/es). This institution was founded in 2002 as a spin-off from Instituto Tecnológico de Monterrey. Tec Monterrey was created in 1943 with an aspiration to become the MIT of Mexico. Over the years, it achieved the status as the fifth highest ranked university in Latin America (https://www.timeshighereducation.com/ world-university-rankings/monterrey-institute-technology). As tuition was high and acceptance standards exclusive, a large percent of the Mexican and Central American population did not have access to such a university. Therefore, Tecmilenio was established as a less expensive alternative. The goal was to make higher education, especially technical education, available to a broader portion of the population. Tuition at Tecmilenio was set at $62 \%$ below that of Tec Monterrey.

Between its founding in 2002 and 2010, Tecmilenio gradually increased enrolments to approximately three thousand students. The trouble is, after these first few years of successful operation, Tecmilenio's enrolment began to 
decline. In 2010, for example, enrolment totalled 3120 students; in 2011, enrolment was 2991 students $(-4 \%)$; and in 2012, enrolment had fallen to 2844 students $(-5 \%)$. The institution had a reputation as a low-cost, secondclass institution, and annual staff turnover averaged almost 100\%. Student retention was only $40 \%$.

The president of Tecmilenio, Hector Escamilla, determined that to turn the institution around, a dramatically different strategy would be required than had been pursued in the past. He hired several key staff members to help him develop and achieve this new strategy. Between 2012 and 2016, the Tecmilenio staff aggressively pursued exposure to experts in positive psychology and POS, including Tal Ben Shahar, Martin Seligman, James Pawelski, Sonja Lyubomirsky, Mihaly Csikszentmihalyi, David Cooperrider, Jane Dutton, and the author. This exposure led to a new model for the university where students, staff, faculty, and alumni would pursue personal and institutional wellbeing and happiness as the primary outcomes of their higher education experience.

Tecmilenio's formal mission was stated as: "We prepare people to flourish, have a purpose in life, and prepare the skills that can help them achieve their purpose in order to benefit society". This new university modelthe creation of the world's first wellbeing and happiness university-was based on three primary characteristics: (1) a customized education experience where students could choose up to $40 \%$ of their coursework (which provided substantial flexibility to pursue marketable competencies); (2) learning by doing approach supported by a competency-based education model, co-op semester, laboratories, faculty members from industry, and industry advisory boards for the campus; and (3) providing practical tools that produced wellbeing, life satisfaction, and happiness in the entire Tecmilenio as well as the Monterrey community. The goal was to reflect positive principles in all facilities, messages, products, services, rituals, and behaviours associated with the institution.

Twelve teams were organized that included representatives from each of the major stakeholder groups of the university (students, staff, faculty, alumni, corporations). As a result of an appreciative inquiry process, teams were charged to develop strategies to achieve the following "how might we" questions:

- How might we increase the positive environment that keeps our students motivated and engaged throughout their studies?

- How might we create day-to-day experiences that are consistently positive for our students? 
- How might we define and implement the behaviours associated with a culture of wellbeing that is lived by all stakeholders of Tecmilenio?

- How might we engage parents to become more committed to living their lives in a way that is consistent with the principles of POS and positive psychology?

- How might we ensure that all subcontractors to the university interact with us according to the principles of POS, positive psychology, and our ecosystem of wellbeing and happiness?

- How might we design and implement our culture so as to be the best place to work for staff and teachers?

- How might we define and implement a set of behaviours we expect our teachers to adopt as they interact with all our stakeholders?

- How might we develop a strong alumni network peopled with those who continue to support the school, each other, and society as a whole?

- How might we define and measure activities that align with the individual elements of our ecosystem?

- How might we ensure that teachers and staff feel a sense of responsibility for the wellbeing of the students?

- How might we develop positive deviance in our alumni who will challenge and lead society for the better?

A variety of positive practices were implemented in pursuit of these questions. For example, all students at Tecmilenio are now required to register for two semester-long classes - one on positive psychology and one on positive organizations. All faculty and all staff members engage in two courses on the same topics and must earn a certificate in those two areas. The campus ecosystem has been redesigned so that rooms are named with positive terms (e.g., compassion room, thriving room, innovation room, energy room) rather than numbers. The menu in the cafeteria was changed to reflect positive eating habits and physical wellbeing. A gratitude wall and interactive spaces were created in the central administration building. A happiness week was sponsored for the entire Monterrey community. An alumni association was created and is gathering 100 inspirational stories representing the achievement of happiness and wellbeing of Tecmilenio graduates (https://www. linkedin.com/in/ferlop89/?originalSubdomain $=\mathrm{mx}$ ). Ongoing and frequent assessments are conducted to measure the wellbeing and thriving of the community, the institution, and the university's members. Weekly leadership meetings are conducted to review the empirical data gathered on multiple aspects of the university's functioning. 
Table 29.1 Evidence of Tecmilenio's transformation: indicators of success in 2018

\begin{tabular}{lc}
\hline Outcome & $\begin{array}{l}\text { Percentage } \\
(\%)\end{array}$ \\
\hline Increase in institution revenues (five years) & 1,379 \\
Students employed in a job that fulfils their purpose in life & 95 \\
Students who recommend Tecmilenio (net promoter score) & 98 \\
Companies that recommend the Tecmilenio internship program & 98 \\
\hline
\end{tabular}

In addition, all students receive a personal coach or mentor in their first two years at Tecmilenio, and with the assistance of that personal coach, all students develop a purpose in life statement during their first semester on campus. This statement is revised during the students' second year, and during their senior year, students put the statement into action by engaging in a full-time 480-hour co-op (internship) project. This project requires students to create an intervention for the organization in which they conduct their coop assignment. The intervention has two primary purposes: (1) It must fulfil the student's purpose in life, and (2) it must apply a positive organizational change in the organization itself.

The results of implementing positive practices and operationalizing a POS philosophy at Tecmilenio have been dramatic. In the last five years, not only has enrolment increased more than $11 \%$ per year-as of now enrolment is now 58,000 students-but revenue growth has been significant. As a private university, Tecmilenio produces a return of between 20 and 40\%, approximately four times the return of the stock market at its best. Table 29.1 exemplifies the results of Tecmilenio's transformation at the end of the 2018 academic year.

\section{Key Practices}

While these cases occurred in very different institutions, there were several elements that are generalizable across settings and organizational types. The successful implementation of POS and the subsequent improvements in performance at the institutional level are associated with several common practices. Examples include:

- Visible and enthusiastic support from senior leaders. These major initiatives require complete dedication from the top of the organization.

- A challenging, positive, and time-bound goal for implementing POS. The 90-in-90 challenge, for example, gave the institution a special target and a specific time frame in which to achieve the goal. This was a major 
motivating factor. The challenge is to identify the next steps after the initial target is achieved.

- Immersive training in POS and positive practices that includes large portions of organizational members and strategic constituencies. As many individuals as possible — especially senior leaders-need to be exposed to evidence supporting the credibility of POS. Examples of practices that have been successfully implemented in other organizations are helpful, but no specific, orchestrated architecture for implementation is needed. Members of the organization are far more innovative and effective than a centralized plan for implementation.

- The availability of empirical research to bolster the veracity and credibility of the POS principles to be implemented. It is not unusual for constituencies to initially interpret POS as soupy, touchy-feely, irrelevant, feel-good advice. Providing empirical evidence that positive practices significantly affect bottom-line performance is helpful for gaining acceptance and involvement in implementation.

- The discretion to try a variety of practices depending on the situation or constituency. No single prescribed process or set of procedures is universally applicable. Organizations themselves are remarkably adept in determining what works in what circumstances. Costa Rica did not implement POS principles in the same way as did Mexico or New Zealand.

- The embedding of POS into the culture of the institution (including vision, values, and the physical environment). This cannot be seen as a program-of-the-month, a fad, or the top leadership's new craze. The reward system, the articulated values, the processes, the physical ecosystem, and the hiring criteria must reflect POS aims.

- The ongoing collection of data for guiding the implementation of POS practices. Not only does data gathering help maintain accountability for progress, but decision-making must be informed by ongoing data trends. The data should be made widely available to all constituencies involved in the implementation of POS practices.

- Unleashing the power of positive energizers. Selecting individuals who exude enthusiasm, vigour, and passion to help lead the effort helps spread the positive virus much faster. Positive energizers should be used as members of the change team.

- A central coordinating entity. At least one individual or office should be the central gathering place for data collection, on-going reporting of best practices, identifying needed resources, and dissemination of progress on an ongoing basis. Keeping the entire community informed on a regular basis is crucial. 


\section{Conclusion}

These case studies illustrate the potential benefits of incorporating POS within educational institutions. In interviews and public presentations, leaders in both of these institutions have been clear in attributing the adoption of POS and positive practices to their institutions' positive performance.

Of course, no one intervention or approach to institutional improvement can account for all positive changes in institutions of higher education; a variety of factors are always at play. These two positive examples are not described in order to propose that POS and positive practices are the only important factors that enhanced Laureate's and Tecmilenio's effectiveness. But the cases do provide examples of how, in a relatively short amount of time, dramatic improvement can occur at the organization level of analysis. This is in addition to the impact on students' experience and learning (which has been documented by many others [e.g., Adler, 2016]).

A key message that emerged from these two investigations is that, in addition to the effects of positive psychology on individuals - especially students - the outcomes of entire institutions can be substantially affected in positive directions by adopting POS practices. This means that all constituencies-from contractors and interns to board members and corporations-can be positively influenced by the application of POS in the institution. Because of this institution-level change, therefore, the reach and impact can extend far beyond the effects of an individual classroom.

\section{References}

Adler, A. (2016). Teaching well-being increases academic performance: Evidence from Bhutan, Mexico, and Peru (Doctoral dissertation, University of Pennsylvania). Retrieved from https://repository.upenn.edu/cgi/viewcontent.cgi?article=3358\& context=edissertations.

Allan, J. (1996). Learning outcomes in higher education. Studies in Higher Education, 21, 93-108.

Allport, G. W. (1960). Becoming: Basic considerations for a psychology of personality. New Haven, CT: Yale University Press.

Aristotle. (2018). Metaphysics XII, 7, 3-4. New York: Dover Publications.

Baker, W., Cross, R., \& Wooten, L. (2003). Positive organizational network analysis and energizing relationships. In K. S. Cameron, J. E. Dutton, \& R. E. Quinn (Eds.), Positive organizational scholarship: Foundations of a new discipline (pp. 328-342). San Francisco: Berrett-Koehler. 
Baker, W. B., \& Gunderson, R. (2005). Zingermans community of businesses. Ross School of Business, Case Center for Positive Organizations, University of Michigan.

Batson, C. D. (1994). Why act for the public good? Four answers. Personality and Social Psychology Bulletin, 20, 603-610.

Bennis, W. (1963). New role for the behavioral sciences: Effecting organizational change. Administrative Science Quarterly, 8(2), 125-165.

Bennis, W. (1969). Organizational development: Its nature, origins, and prospects. Reading, MA: Addison Wesley.

Bowen, H. (1977). Investment in learning: The individual and social value of American higher education. San Francisco: Jossey-Bass.

Bright, D. S., Cameron, K. S., \& Caza, A. (2006). The amplifying and buffering effects of virtuousness in downsized organizations. Journal of Business Ethics, 64, 249-269.

Cameron, K. S. (1978). Measuring organizational effectiveness in institutions of higher education. Administrative Science Quarterly, 23, 604-632.

Cameron, K. S. (1980). Critical questions in assessing organization effectiveness. Organizational Dynamics, 9, 66-80.

Cameron, K. S. (1981). The enigma of organizational effectiveness. In D. Baugher (Ed.), New directions for program evaluation: Assessing effectiveness (pp. 1-13). San Francisco, CA: Jossey-Bass.

Cameron, K. S. (2003). Organizational virtuousness and performance. In K. S. Cameron, J. E. Dutton, \& R. E. Quinn (Eds.), Positive organizational scholarship: Foundations of a new discipline (pp. 48-65). San Francisco: Berrett-Koehler.

Cameron, K. S. (2008). Paradox in positive organizational change. Journal of Applied Behavioral Science, 44, 7-24.

Cameron, K. S. (2010). Organizational effectiveness. Northampton, MA: Edward Elgar.

Cameron, K. S. (2012). Positive leadership. San Francisco: Berrett Koehler.

Cameron, K. S. (2013). Practicing positive leadership. San Francisco: Berrett Koehler.

Cameron, K. S. (2014). Advances in positive organizational scholarship. In A. B. Bakker (Ed.), Advances in positive organizational psychology (pp. 23-44). Bingley, UK: Emerald.

Cameron, K. S. (2017). Paradox in positive organizational scholarship. In M. Lewis, W. Smith, P. Jarzabkowski, \& A. Langley (Eds.), Oxford handbook of Paradox (Chapter 11). London: Oxford University Press.

Cameron, K. S., Bright, D., \& Caza, A. (2004). Exploring the relationships between organizational virtuousness and performance. American Behavioral Scientist, 47, 766-790.

Cameron, K. S., \& Caza, A. (2002). Organizational and leadership virtues and the role of forgiveness. Journal of Leadership and Organizational Studies, 9, 33-48.

Cameron, K. S., \& Lavine, M. (2006). Making the impossible possible: Leading extraordinary performance-The rocky flats story. San Francisco: Berrett Koehler. 
Cameron, K. S., \& Powley, E. (2008). Implementing positive organizational scholarship at Prudential. Ann Arbor, MI: WDI Publishing.

Cameron, K. S., Dutton, J. E., \& Quinn, R. E. (2003). Positive organizational scholarship: Foundations of a new discipline. San Francisco: Berrett-Koehler.

Cameron, K. S., Mora, C., Leutscher, T., \& Calarco, M. (2011). Effects of positive practices on organizational effectiveness. Journal of Applied Behavioral Science, 47, 266-308.

Cameron, K. S., \& Plews, E. (2012). Positive leadership in action: Applications of positive organizational Scholarship by Jim Mallozzi. Organizational Dynamics, 41, 99-105.

Cameron, K. S., \& Spreitzer, G. M. (2012). Oxford handbook of positive organizational scholarship. New York: Oxford University Press.

Chun, R. (2005). Ethical character and virtue of organizations: An empirical assessment and strategic implications. Journal of Business Ethics, 57, 269-284.

Cialdini, R. B. (2000). Influence: The science of persuasion. New York: Allyn Bacon.

Clifton, D. O., \& Harter, J. K. (2003). Investing in strengths. In K. S. Cameron, J. E. Dutton, \& R. E. Quinn (Eds.), Positive organizational scholarship: Foundations of a new discipline (pp. 111-121). San Francisco: Berrett-Koehler.

Comte-Sponville, A. (2001). A small treatise of the great virtues (Trans., C. Temerson). New York: Metropolitan Books.

Cooperrider, D. L., \& Srivastva, S. (1987). Appreciative inquiry in organizational life. In W. Pasmore \& E. Woodman (Eds.), Research in organization change and development (Vol. 1). Greenwich, CT: JAI Press.

Davis, G. F., \& Marquis, C. (2005). Prospects for organizational theory in the early twenty-first century: Institutional fields and mechanisms. Organization Science, 16, 332-343.

Diener, E. (1984). Subjective well-being. Psychological Bulletin, 95, 542-575.

Diener, E. (2009). The collected work of Ed Diener-The science of well-being, culture and well-being, and assessing well-being. New York: Springer.

Dutton, J. E., \& Glynn, M. (2007). Positive organizational scholarship. In C. Cooper \& J. Barling (Eds.), Handbook of organizational behavior. Thousand Oaks, CA: Sage.

Dutton, J. E., \& Glynn, M. (2008). Positive organizational scholarship. In C. Cooper, \& J. Barling (Eds.), Handbook of organizational behavior (pp. 693-711). Thousand Oaks: Sage.

Dutton, J. E., \& Heaphy, E. (2003). The power of high quality connections. In K. S. Cameron, J. E. Dutton, \& R. E. Quinn (Eds.), Positive organizational scholarship: Foundations of a new discipline (pp. 263-278). San Francisco: Berrett-Koehler.

Dutton, J. E., \& Sonenshein, S. (2009). Positive organizational scholarship. In S. Lopez (Ed.), Encyclopedia of positive psychology (pp. 737-742). Oxford: WileyBlackwell.

Dutton, J. E., Worline, M. C., Frost, P. J., \& Lilius, J. M. (2006). Explaining compassion organizing. Administrative Science Quarterly, 51, 59-96. 
Emmons, R. A. (1999). The psychology of ultimate concerns: Motivation and spirituality in personality. New York: Guilford Press.

Erhard-Seibold, E. V. (1937). The heliotrope tradition. Orisis, 3, 22-46.

Fowers, B. J., \& Tjeltveit, A. C. (2003). Virtue obscured and retrieved: Character, community, and practices in behavioral science. American Behavioral Scientist, 47(4), 387-394.

Fredrickson, B. L. (2009). Positivity. New York: Crown.

Fredrickson, B. L., \& Joiner, T. (2002). Positive emotions trigger upward spirals toward emotional well-being. American Psychologist, 13, 172-175.

Gallagher, M. W., Lopez, S. J., \& Preacher, K. J. (2009). The hierarchical structure of well-being. Journal of Personality, 77, 1025-1049.

Gittell, J. H., Cameron, K., Lim, S., \& Rivas, V. (2006). Relationships, layoffs, and organizational resilience: Airline industry responses to September 11. The Journal of Applied Behavioral Science, 42(3), 300-328.

Godfrey, P. C. (2003). The relationship between corporate philanthropy and shareholder wealth: A risk management perspective. Academy of Management Review, 30(4), 777-796.

Goshal, S. (2005). Bad management theories are destroying good management practices. Academy of Management Learning and Education, 4, 75-91.

Grant, A. M., \& Schwartz, B. (2011). Too much of a good thing: The challenges and opportunity of the Inverted-U. Perspectives in Psychological Science, 6(1), 6176.

Guzzo, R. A., \& Dickson, M. W. (1996). Teams in organizations: Recent research on performance and effectiveness. Annual Review of Psychology, 47, 307-338.

Hess, E. D., \& Cameron, K. S. (2006). Leading with values: Positivity, virtue, and high performance. Cambridge: Cambridge University Press.

Ilies, R., Nahrgang, J. D., \& Morgeson, F. O. (2007). Leader-member exchange and citizenship behaviors: A meta-analysis. Journal of Applied Psychology, 92, 269-277.

Jahoda, M. (1959). Current concepts of positive mental health. New York: Basic Books.

James, W. (1902). The varieties of religious experience: A study in human nature. Washington, DC: Library of America.

Jensen, M. C. (2002). Value maximization, stakeholder theory, and the corporate objective function. Business Ethics Quarterly, 12, 235-256.

Keyes, C. L. M. (2005). Mental illness and/or mental health? Investigating axioms of the complete state model of health. Journal of Consulting and Clinical Psychology, 73, 539-548.

Kramer, R. M. (1999). Trust and distrust in organizations: Emerging perspectives, enduring questions. Annual Review of Psychology, 50, 569-598.

Lee, F., Caza, A., Edmondson, A., \& Thomke, St. (2003). New knowledge creation in organizations. In K. S. Cameron, J. E. Dutton, \& R. E. Quinn (Eds.), Positive organizational scholarship: Foundations of a new discipline (pp. 194-206). San Francisco: Berrett-Koehler.

Liu, O. L. (2011a). An overview of outcomes assessment in higher education. Educational Measurement: Issues and Practice, 30, 2-9. 
Liu, O. L. (2011b). Value-added assessment in higher education: A comparison of two methods. Higher Education, 61, 445-461.

Loeb, J., \& Northrop, J. H. (1917). Heliotropic animals as photometers on the basis of the validity of the Bunsen-Roscoe Law for Heliotropic Reactions. Proceedings of the National Academy of Sciences, 3, 539-544.

Losada, M., \& Heaphy, E. (2004). The role of positivity and connectivity in the performance of business teams: A nonlinear dynamics model. American Behavioral Scientist, 47(6), 740-765.

Luthans, F., Norman, S. M., Avolio, B. J., \& Avey, J. B. (2008). The mediating role of psychological capital in the supportive organizational climate-employee performance relationship. Journal of Organizational Behavior, 29, 219-238.

Lyubomirsky, S., King, L., \& Diener, E. (2005). The benefits of frequent positive affect: Does happiness lead to success? Psychological Bulletin, 131(6), 803-855.

Makhoul, S. (2019). Higher education accreditation, quality assurance and their impact to teaching and learning enhancement. Journal of Economic and Administrative Sciences, 35, 235-250.

Maslow, A. (1965). Eupsychian management: A journal. Homewood, IL: IrwinDorsey.

Maslow, A. H. (1968). Toward a psychology of being. New York: Van Nostrand.

McCullough, M. E., \& Snyder, C. R. (2001). Classical sources of human strength: Revisiting an old home and building a new one. Journal of Social and Clinical Psychology, 19, 1-10.

McGregor, D. (1960). The human side of enterprise. New York: McGraw-Hill.

Moore, G., \& Beadle, R. (2006). In search of organizational virtue in business: Agents, goods, practices, institutions, and environments. Organization Studies, 27, 369-389.

Northrop, J. H., \& Loeb, J. (1923). The photochemical basis of animal heliotropism. Journal of General Physiology, 5, 581-595.

Organ, D. W. (1988). Organizational citizenship behavior: The good soldier syndrome. Lexington, MA: Lexington Books.

Park, N., \& Peterson, C. M. (2003). Virtues and organizations. In K. S. Cameron, J. E. Dutton, \& R. E. Quinn (Eds.), Positive organizational scholarship: Foundations of a new discipline (pp. 33-47). San Francisco: Berrett Koehler.

Peterson, C., \& Seligman, M. E. P. (2004). Character strengths and virtues. New York: Oxford University Press.

Pfeffer, J. (2010). Building sustainable organizations: The human factor. Academy of Management Perspectives, 8, 34-45.

Podsakoff, P. M., Mackenzie, S. B., Paine, J. B., \& Bachrach, D. G. (2000). Organizational citizenship behaviors: A critical review of the theoretical and empirical literature and suggestions for future research. Journal of Management, 26, 513-563.

Powley, E. H., \& Piderit, K. (2008). Tending wounds: Elements of the organizational healing process. Journal of Applied Behavioral Science, 44(1), 134-149. 
Pursglove, J., \& Simpson, M. (2007). Benchmarking the performance of English universities. Benchmarking: An International Journal, 14, 102-122.

Quinn, R. W. (2002). Flow in knowledge work: High performance experience in the design of national security technology. Administrative Science Quarterly, 50, 610-642.

Sandage, S. J., \& Hill, P. C. (2001). The virtues of positive psychology: The rapprochement and challenges of the affirmative postmodern perspective. Journal for the Theory of Social Behavior, 31, 241-260.

Scheier, M. F., Carver, C. S., \& Bridges, M. W. (1994). Distinguishing optimism from neuroticism (and trait anxiety, self-mastery, and self-esteem): A reevaluation of the Life Orientation Test. Journal of Personality and Social Psychology, 67(6), 1063-1078.

Seligman, M. E. P., Ernst, R. M., Gillham, J., Reivich, K., \& Linkins, M. (2009). Positive education: Positive psychology and classroom interventions. Oxford Review of Education, 35, 293-311.

Smith, P. C., Kendall, L. M., \& Hulin, C. L. (1969). The measurement of satisfaction in work and retirement. Chicago: Rand McNally.

Spreitzer, G., Sutcliffe, K., Dutton, J., Sonenshein, S., \& Grant, A. (2005). A socially embedded model of thriving at work. Organization Science, 16(5), 537-549.

Spreitzer, G. M., \& Sonenshein, S. (2003). Positive deviance and extraordinary performance. In K. S. Cameron, J. E. Dutton, \& R. E. Quinn (Eds.), Positive organizational scholarship: Foundations of a new discipline (pp. 207-224). San Francisco: Berrett-Koehler.

Sutcliffe, K. M., \& Vogus, T. J. (2003). Organizing for resilience. In K. S. Cameron, J. E. Dutton, \& R. E. Quinn (Eds.), Positive organizational scholarship: Foundations of a new discipline (pp. 94-110). San Francisco: Berrett-Koehler.

Thrash, T. M., \& Elliot, A. J. (2003). Inspiration as a psychological construct. Journal of Personality and Social Psychology, 84(4), 871-889.

Tutu, D. (1999). No future without forgiveness. New York: Doubleday.

Vanette, D., Cameron, K. S., \& Powley, E. (2006). Implementing positive organizational scholarship at Prudential. Michigan: Ross School of Business, Center for Positive Organizations.

Vianello, M., Galliani, E. M., \& Haidt, J. (2010). Elevation at work: The effects of leaders' moral excellence. Journal of Positive Psychology, 4, 105-127.

Waters, L., Sun, J., Rusk, R., Cotton, A., \& Arch, A. (2015). Well-being and positive functioning in students. In M. Slade, L. Oades, \& A. Jarden (Eds.), Wellbeing, recovery, and mental health (pp. 245-264). New York: Cambridge University Press.

Weber, M. (1997). The theory of social and economic organization. New York: Free Press.

Weick, K. E. (2003). Positive organizing and organizational tragedy. In K. S. Cameron, J. E. Dutton, \& R. E. Quinn (Eds.), Positive organizational scholarship: Foundations of a new discipline (pp. 66-80). San Francisco: Berrett-Koehler. 
Whetten, D. A. (1980). Organizational decline. Academy of Management Review, 5, 577-588.

Whetten, D. A., \& Cameron, K. S. (2020). Developing management skills (10th ed.). London: Pearson.

White, M., \& Murray, S. (2015). Evidence based approaches in positive education. London: Springer.

Worline, M. C., \& Quinn, R. W. (2003). Courageous principled action. In K. S. Cameron, J. E. Dutton, \& R. E. Quinn (Eds.), Positive organizational scholarship: Foundations of a new discipline (pp. 138-158). San Francisco: Berrett-Koehler.

Worthington, E. L. (2001). Unforgiveness, forgiveness, and reconciliation and their implications for societal interventions. In R. G. Helmick \& R. L. Petersen (Eds.), Forgiveness and reconciliation: Religion, public policy, and conflict transformation (pp. 161-182). Philadelphia: Templeton Foundation Press.

Wright, T. A., \& Goodstein, J. (2007). Character is not dead in management research: A review of individual character and organization-level virtue. Journal of Management, 33, 928-948.

Wrzesniewski, A. (2003). Finding positive meaning in work. In K. S. Cameron, J. E. Dutton, \& R. E. Quinn (Eds.), Positive organizational scholarship: Foundations of a new discipline (pp. 296-308). San Francisco: Berrett-Koehler.

Open Access This chapter is licensed under the terms of the Creative Commons Attribution 4.0 International License (http://creativecommons.org/licenses/by/4.0/), which permits use, sharing, adaptation, distribution and reproduction in any medium or format, as long as you give appropriate credit to the original author(s) and the source, provide a link to the Creative Commons license and indicate if changes were made.

The images or other third party material in this chapter are included in the chapter's Creative Commons license, unless indicated otherwise in a credit line to the material. If material is not included in the chapter's Creative Commons license and your intended use is not permitted by statutory regulation or exceeds the permitted use, you will need to obtain permission directly from the copyright holder.

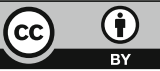

